\title{
PENGARUH KONFLIK INTERPERSONAL, BEBAN KERJA, DAN KOMUNIKASI TERHADAP STRES KERJA KARYAWAN PT. VIKING ENGINEERING BATAM
}

\author{
Esther Endang Dwi Lestari ${ }^{1}$, Sri Langgeng Ratnasari ${ }^{2}$ \\ ${ }^{1}$ Program Studi Manajemen, Fakultas Ekonomi, Universitas Riau Kepulauan, Indonesia \\ estherlestari22@gmail.com \\ ${ }^{2}$ Program Studi Magister Manajemen, Program Pascasarjana, Universitas Riau Kepulauan, Indonesia \\ sarisucahyo@yahoo.com
}

\begin{abstract}
Abstrak
Penelitian ini bertujuan untuk mengetahui pengaruh konflik interpersonal, beban kerja, dan komunikasi baik secara simultan maupun parsial terhadap stres kerja karyawan PT. Viking Engineering Batam. Sampel penelitian ini adalah 57 karyawan. Teknik analisis dalam penelitian ini menggunakan uji validitas, uji reliabilitas, uji asumsi klasik, analisis regresi linear berganda, uji t, uji F, dan uji R2. Metode yang digunakan adalah metode deskriptif kualitatif, yaitu pengukuran data statistik obyektif dengan pengolahan data menggunakan software SPSS 20.0. Hasil penelitian menunjukkan bahwa konflik interpersonal, beban kerja, dan komunikasi secara simultan berpengaruh signifikan terhadap stress kerja karyawan PT. Viking Engineering Batam, hal ini dibuktikan dengan uji $\mathrm{F}$ yang menunjukkan nilai signifikan 0,003 lebih kecil dari 0,05 . Hasil uji t menunjukkan bahwa konflik interpersonal dan beban kerja secara parsial berpengaruh tetapi tidak signifikan, hal ini dibuktikan dengan uji t yang menunjukkan hasil nilai signifikan lebih dari 0,05 yaitu sebesar 0,552 untuk variabel konflik interpersonal dan 0,590 untuk variabel beban kerja. Tetapi hasil uji t menunjukkan bahwa komunikasi secara parsial berpengaruh signifikan terhadap stress kerja, hal ini dibuktikan dengan uji t yang menunjukkan nilai signifikan lebih kecil dari 0,05 yaitu sebesar 0,002. Kata Kunci: Konflik Interpersonal, Beban Kerja, Komunikasi, Stress Kerja.
\end{abstract}

\begin{abstract}
The purpose of this research is to find out the influence of interpersonal conflict, workload, and communication either simultaneously and partially to the employees' job stress of PT. Viking Engineering Batam. The research sample are 57 employees'. Analysis technique in this research use validity test, reliability test, classical assumption test, multiple linear regressions, $t$ test, $F$ test and $R 2$ test. The method used is descriptive qualitative, that is measurement of objective statistic data with data processing using software SPSS 20.0. The results showed that interpersonal conflict, workload, and communication simultaneously have a significant influence to the employees' job stress of PT. Viking Engineering Batam, it has been proven by using F-test which shows that the significant value is 0,003 lest than 0,05. The result of $t$ test shows that interpersonal conflict and workload is partially influential but not significant, it is proved by t-test that shows result of significant value more than 0,05 which is 0,552 for the interpersonal conflict and 0,590 for the workload. But the result $t$ test show that partially communication have significant influence to the employees' job stress, it has been proven by using t-test which shows that the significant value less than 0,05 which is 0,002.

Keywords: Interpersonal Conflict, Workload, Communication, Job Stress.
\end{abstract}




\section{PENDAHULUAN}

Kemajuan serta ketahanan suatu perusahaan, dipengaruhi oleh sumber daya manusia di perusahaan tersebut. Hal ini dikarenakan kinerja karyawan sangat menentukan hasil dari produktifitas perusahaan. Aset paling penting yang harus dimiliki organisasi atau perusahaan dan harus dipertahankan adalah sumber daya manusia, Samsudin (2009). Kinerja merupakan kesuksesan seseorang dalam melaksanakan pekerjaan, Ratnasari (2013).

Stres merupakan satu masalah yang tidak dapat dihindari oleh setiap orang dan seringkali banyak memberikan efek negatif terhadap kesehatan maupun kinerja seseorang. Stres di lingkungan kerja dapat terjadi pada setiap level manajemen mulai dari top of management sampai pada karyawan biasa.Stres kerja merupakan perasaan tertekan yang dialami karyawan dalam menghadapi pekerjaan ataupun suatu kondisi ketegangan yang mempengaruhi emosi, proses berpikir dan kondisi seseorang, Yuliawan (2012).

Stres dapat menyebabkan dampak positif maupun negatif. Dampak negatif ditinjau dari efek stres terhadap kesehatan yaitu menyebabkan gangguan baik mental maupun fisik yang menyerang stabilitas fungsi kerja organ tubuh. Selain itu, stres berdampak pada karir karena apabila stres akan mengakibatkan penurunan stabilitas dan daya tahan tubuh maka kinerja individu akan menurun. Tetapi di sisi lain stres juga berdampak positif yaitu, sebagai motivator yang digunakan sebagai pemicu peningkatan kinerja karyawan.

Faktor yang mengakibatkan terjadinya stres kerja sangat beragam antara lain; konflik individu internal perusahaan maupun eksternal, beban kerja yang berlebih, lingkungan kerja, komunikasi dalam lingkup pekerjaan, perubahan sosial dan teknologi. Dari hasil observasi pada karyawan di PT. Viking Engineering Batam yang berjumlah 130 karyawan, terjadinya stres kerja disebabkan oleh adanya konflik interpersonal, beban kerja dan komunikasi dalam lingkungan kerja. Dimana beberapa karyawan menghadap langsung kepada $H R$ Departmen guna konsultasi akan kondisi yang dirasakan.Objek penelitian ini adalah PT. Viking Engineering Batam yang bergerak di bidang industri logam dasar baja atau perbaikan kapal. Perusahaan ini merupakan perusahaan yang mengerjakan docking repair kapal mapun pembuatan modul sesuai dengan permintaan konsumennya.

Karyawan pada PT. Viking Engineering Batam dihadapkan dengan berbagai kondisi pekerjaan yang tingkat resiko pengerjaannya sangat tinggi. Mereka dituntut untuk bekerja sesuai dengan standar yang ditentukan oleh perusahaan serta disesuaikan dengan jadwal projek yang ada, sementara itu karyawan perlu mendapatkan perhatian dari perusahaan. 
Kondisi tersebut tentunya akan menimbulkan stres kerja dan daat berpengaruh terhadap menurunnya kinerja. Oleh sebab itu penting bagi PT. Viking Engineering Batam untuk memenuhi kebutuhan karyawan dan menciptakan kenyamanan kerja agar dapat meminimalisir terjadinya stres kerja serta dapat meningkatkan kinerja karyawan.

1. Rumusan Masalah

Berdasarkan batasan masalah yang telah diuraikan di atas, maka rumusan masalah pada penelitian ini adalah sebagai berikut:

1. Apakah konflik interpersonal berpengaruh terhadap stres kerja karyawan PT. Viking Engineering Batam?

2. Apakah beban kerja berpengaruh terhadap stres kerja karyawan PT. Viking Engineering Batam?

3. Apakah komunikasi berpengaruh terhadap stres kerja karyawan PT. Viking Engineering Batam?

4. Apakah konflik interpersonal, beban kerja, dan komunikasi secara bersama-sama berpengaruh terhadap stres kerja karyawan PT. Viking Engineering Batam?

2. Tujuan Penelitian

Tujuan yang hendak dicapai dalam penelitian ini adalah:

1. Untuk mengetahui pengaruh konflik interpersonal terhadap stres kerja karyawan PT. Viking Engineering Batam.

2. Untuk mengetahui pengaruh beban kerja terhadap stres kerja karyawan PT. Viking Engineering Batam.

3. Untuk mengetahui pengaruh komunikasi terhadap stres kerja karyawan PT. Viking Engineering Batam.

4. Untuk mengetahui pengaruh konflik interpersonal, beban kerja, dan komunikasi terhadap stres kerja karyawan PT. Viking Engineering Batam.

3. Tinjauan Pustaka

Definisi Konflik Interpersonal

Scannell (2010) konflik adalah suatu hal alami dan normal yang timbul karena perbedaan persepsi, tujuan atau nilai dalam sekelompok individu. Konflik interpersonal atau konflik antara dua atau lebih individu diakibatkan oleh banyak faktor, yang sering terjadi adalah karena adanya perbedaan kepribadian, Dewi dan Handayani (2013).Konflik interpersonal dapat diukur menggunakan indikator menurut, Fitriana (2013) antara lain: 1) 
Kesalahan komunikasi, 2) Perbedaan tujuan, 3) Perbedaan persepsi, 4) Interdependensi aktivitas kerja, 5) Kesalahan dalam afeksi.

Definisi Beban Kerja

Beban kerja menurut Meshkati, dalam Hariyati (2011) dapat didefinisikan sebagai suatu perbedaan antara kapasitas atau kemampuan pekerja dengan tuntutan pekerjaan yang harus dihadapi. Kategori lain dari beban kerja adalah kombinasi dari beban kerja kuantitatif dan kualitatif.Beban kerja dapat diukur menggunakan indikator antara lain: 1) Target yang harus dicapai, 2) Kondisi pekerjaan, 3) Standar pekerjaan.

Definisi Komunikasi

Komunikasi adalah pertukaran pesan verbal maupun non verbal antara si pengirim dengan si penerima pesan untuk mengubah tingkah laku, Hasby (2017). Dengan adanya komunikasi efektif yang baik antar sesama individu dalam suatu organisasi atau perusahaan, dapat menciptakan kenyamanan dalam suasana pekerjaan serta meminimaisir terjadinya kesalahpahaman informasi ataupun penyampaian interpersonal.Dapat diukur menggunakan indikator menurut, Suranto (2010) antara lain: 1) Pemahaman, 2) Kesenangan, 3) Pengaruh pada sikap, 4) Hubungan yang makin baik, 5) Tindakan.

\section{Definisi Stres Kerja}

Stres kerja menurut Handoko (2011) adalah suatu kondisi ketegangan yang mempengaruhi emosi, proses berpikir dan kondisi seseorang.Stres yang terlalu besar dapat mengancam kemampuan seseorang untuk menghadapi lingkungan. Sebagai hasilnya, pada diri para karyawan berkembang berbagai macam gejala stres yang dapat mengganggu pelaksanaan kerja mereka. Dapat diukur menggunakan indikator menurut, Sari (2015) antara lain: 1) Intimidasi, 2) Ketidakcocokan dengan pekerjaan, 3) Pekerjaan yang berbahaya, 4) Beban berlebih, 5) Harapan yang tidak realistis.

Hipotesis

Berdasarkan tinjuan teoritis dan hasil temuan empiris di atas, maka hipotesis yang diajukan dalam penelitian ini adalah:

H1 : Konflik Interpersonal berpengaruh signifikan terhadap Stres Kerja karyawan PT. Viking Engineering.

H2 : Beban Kerja berpengaruh signifikan terhadap Stres Kerja karyawan PT. Viking Engineering. 
H3 : Komunikasi berpengaruh signifikan terhadap Stres Kerja karyawan PT. Viking Engineering.

H4 : Konflik Interpersonal, Beban Kerja, dan Komunikasi secara bersama-sama berpengaruh signifikan terhadap Stres Kerja karyawan PT. Viking Engineering.

\section{METODOLOGI}

\section{Objek Penelitian}

Objek penelitian adalah sasaran ilmiah untuk mendapatkan data dengan tujuan dan kegunaan tertentu tentang sesuatu hal objektif, valid, dan reliable tentang suatu hal (variabel tertentu), Sugiyono (2012). Objek penelitian ini adalah karyawan PT. Viking Engineering Batam.

\section{Populasi Dan Sampel}

Populasi dalam penelitian ini adalah karyawan PT. Viking Engineering Batam yang berjumlah 130 orang. Dalam penelitian ini penulis mempersempit populasi dengan menghitung ukuran sampel menggunakan teknik Slovin. Rumus Slovin untuk menentukan sampel adalah:

$$
n=\frac{N}{1+n e^{2}}
$$

Jadi berdasarkan penghitungan diatas jumlah sampel sebesar 57 responden

\section{Sumber Data}

Data yang digunakan dalam penelitian di PT. Viking Engineering Batam adalahdata primer dan data sekunder. Data primer adalah data yang mengacu pada informasi yang diperoleh dari tangan pertama oleh peneliti yang berkaitan dengan variabel minat untuk tujuan spesifik studi. Data sekunder adalah data yang mengacu pada informasi yang dikumpulkan dari sumber yang telah ada.

\section{Teknik Pengumpulan Data}

Apabila dilihat dari sumber pengumpulan data (data primer dan data sekunder), maka teknik pengumpulan data dapat dilakukan dengan interview, kuesioner (angket), observasi, Sugiyono (2012).

Definisi Operasional

Variabelin dependen(variabel bebas)

Yang menjadi variabel bebas dalam penelitian ini antara lain: 


$$
\begin{aligned}
& \mathrm{X} 1=\text { Konflik Interpersonal } \\
& \mathrm{X} 2=\text { Beban Kerja } \\
& \mathrm{X} 3=\text { Komunikasi }
\end{aligned}
$$

Variabel Dependen (variabel terikat)

Variabel terikat adalah variabel yang dijelaskan atau dipengaruhi oleh variabel bebas. Dalam penelitian ini variabel terikatnya:

$$
\mathrm{Y}=\text { Stres Kerja }
$$

Teknik Analisis Data

\section{Uji Vadilitas}

Menurut Sugiyono (2010) validitas dalam penelitian dijelaskan sebagai salah satu derajat ketepatan pengukuran tentang isi dari pernyataan yang penulis buat. Kriteria pada pengujian validitas dilakukan dengan membandingkan $r$ hitung dan $r$ tabel. Jika $r$ hitung $>r$ tabel maka item pernyataan tersebut dapat dikatakan valid. Nilai $r$ hitung diambil dalam kolom correlated item-total correlation, sedangkan $\mathrm{r}_{\text {tabel }}$ ditentukan menggunakan rumus df $=\mathrm{n}-2$.

\section{Uji Reliabilitas}

Instrumen yang reliabel adalah instrumen yang apabila digunakan beberapa kali untuk mengukur obyek yang sama, akan menghasilkan data yang sama. Reliabilitas variabel ditentukan berdasarkan nilai cronbach alpha, apabila nilai alpha lebih besar dari 0,6 maka dikatakan variabel tersebut reliabel atau dapat diandalkan.

\section{Uji Asumsi Klasik}

Uji asumsi klasik bertujuan untuk melihat layak atau tidaknya model regresi yang digunakan untuk memprediksi variabel terikat berdasarkan masukan variabel bebasnya, maka model regresi harus terbebas dari beberapa asumsi antara lain:

\section{Uji Normalitas}

Uji normalitas digunakan untuk menguji apakah dalam model regresi variabel dependent dan variabel independent keduanya mempunyai distribusi normal atau tidak (Ghozali, 2013)

\section{Uji Multikolinearitas}

Uji multikolinearitas bertujuan untuk menguji apakah dalam regresi ditemukan adanya kolerasi antar variabel bebas (Independent), Ghozali (2013). Model regresi yang baik 
seharusnya tidak terjadi korelasi diantara variabel independen. Apabila nilai Tolerance $<0,10$ atau sama dengan nilai VIF > 10 maka dapat dikatakan bahwa model regresi terdapat gejala multikolinearitas dan sebaliknya.

\section{Uji Heteroskedastisitas}

Menurut Ghozali (2013) uji heteroskedastisitas yaitu untuk menguji apakah dalam model regresi terjadi ketidaksamaan variance dari residual satu pengamatan ke pengamatan yang lain.Menurut Ghozali (2011) model regresi yang baik adalah yang homoskedastisitas atau tidak terjadi heteroskedastisitas. Jika $\mathrm{p}$ value $>0,05$ tidak signifikan berarti tidak terjadi heteroskedastisitas artinya model regresi lolos uji heteroskedastisitas.

\section{Pengujian Hipotesis}

Analisis Regresi Linier Berganda

Analisis regresi linier berganda digunakan untuk mengukur ada atau tidaknya pengaruh antara variabelindependen (bebas) dengan variabeldependen (terikat).

Uji T (Parsial)

Uji ini digunakan untuk mengetahui apakah masing-masing variabel bebasnya secara sendiri-sendiri berpengaruh secara signifikan terhadap variabel terikatnya. Dengan ketentuan t hitung >t tabel atau probabilitas kesalahan kurang dari $5 \%$ maka membuktikan variabel bebas secara parsial berpengaruh signifikan terhadap variabel tidak bebas, Ha diterima dan Ho ditolak.

\section{Uji F (Simultan)}

Uji ini digunakan untuk mengetahui pengaruh secara bersama-sama (simultan) variabel bebas terhadap variabel terikat, dimana Fhitung > Ftabel, maka H1 diterima atau secara bersama-sama variabel bebas dapat menerangkan variabel terikatnya secara serentak.

\section{Uji $\mathrm{R}^{2}$}

Uji R2 dimaksudkan untuk mengukur kemampuan seberapa besar persentase variasi variabel bebas (independen) pada model regresi linier berganda dalam menjelaskan variasi variabel terikat (dependen). Dengan kata lain pengujian model menggunakan R2, Nilai Koefisien determinasi adalah antara 0 (nol) dan 1 (satu). Nilai $\mathrm{R}^{2}$ yang kecil (nol) berarti kemampuan variabel-variabel bebas (konflik interpersonal, beban kerja, dan komunikasi) dalam menjelaskan variasi variabel terikat (stress kerja) amat terbatas. 


\section{PEMBAHASAN}

Karakteristik Responden Berdasarkan Usia

Hasil penelitian ini dilihat dari karakteristik responden berdasarkan usia dapat dilihat pada Tabel 1.

Tabel 1. Karakteristik Responden Berdasarkan Usia

\begin{tabular}{ccc}
\hline Keterangan Usia & Frekuensi & Presentase \\
\hline$\leq 30$ tahun & 13 & $22,8 \%$ \\
$30-40$ tahun & 12 & $21,2 \%$ \\
$41-50$ tahun & 23 & $40,4 \%$ \\
$\geq 50$ tahun & 9 & $15,8 \%$ \\
Jumlah & 57 & $100 \%$ \\
\hline
\end{tabular}

Sumber: Data Primer yang diolah, 2018

Berdasarkan Tabel 1 maka dapat disimpulkan bahwa mayoritas responden memiliki umur antara 41-50 tahun, dimana di usia tersebut memang rentan mengalami stres dalam bekerja.

Karakteristik Responden Berdasarkan Jenis Kelamin

Hasil penelitian ini apabila dilihat dari karakteristik responden berdasarkan jenis kelamin dapat dilihat pada Tabel 2.

Tabel 2. Karakteristik Responden Berdasarkan Jenis Kelamin

\begin{tabular}{ccc}
\hline Keterangan Jenis Kelamin & Jumlah & Presentase \\
\hline Laki - laki & 50 & $87,7 \%$ \\
Perempuan & 7 & $12,3 \%$ \\
Jumlah & 57 & $100 \%$ \\
\hline Sumber: Data Primer yang diolah 2018 & &
\end{tabular}

Hasil frekuensi jawaban responden berdasarkan jenis kelamin menunjukkan baha mayoritas karyawan PT. Viking Engineering berjenis kelamin laki-laki dikarenakan, perusahaan tersebut memang bergerak di bidang galangan kapal dimana setiap lini pekerjaan lebih banyak dibutuhkan pekerja laki-laki.

Karakteristik Responden Berdasarkan Tingkat Pendidikan

Hasil penelitian ini apabila dilihat dari karakteristik responden berdasarkan tingkat pendidikan dapat dilihat pada Tabel 3. 
Tabel 3. Karakteristik Responden Berdasarkan Tingkat Pendidikan

\begin{tabular}{ccc}
\hline Keterangan Pendidikan & Jumlah & Presentase \\
\hline SMA & 34 & $59,60 \%$ \\
D3 & 6 & $10,50 \%$ \\
S1 & 16 & $28,10 \%$ \\
S2 & 1 & $1,80 \%$ \\
Jumlah & 57 & $100 \%$ \\
\hline
\end{tabular}

Sumber: Data Primer yang diolah, 2018

Berdasarkan data pada Tabel 3 tersebut dapat disimpulkan bahwa mayoritas responden memiliki tingkat pendidikan terakhir SMA karena, kualifikasi yang dibutuhkan dalam pekerjaan di bidang galangan kapal lebih pada skill yang ditunjang dengan adanya pelatihanpelatihan maupun pengalaman di bidang nya.

\section{Karakteristik Responden Berdasarkan Lama Bekerja}

Hasil penelitian ini apabila dilihat dari karakteristik responden berdasarkan lama bekerja pada Tabel 4.

\section{Tabel 4. Karakteristik Responden Berdasarkan Lama Bekerja}

\begin{tabular}{ccc}
\hline Keterangan Lama Bekerja & Jumlah & Presentase \\
\hline$\leq 2$ tahun & 7 & $12,3 \%$ \\
$2-3$ tahun & 28 & $49,1 \%$ \\
$\geq 3$ tahun & 22 & $38,6 \%$ \\
Jumlah & 57 & $100 \%$ \\
\hline
\end{tabular}

Berdasarkan hasil jawaban responden dapat disimpulkan bahwa mayoritas reponden telah memiliki masa kerja 2-3 tahun.

\section{Hasil Uji Validitas}

Uji validitas digunakan untuk mengukur sah dan valid tidaknya suatu kuesioner. Kuesioner dikatakan valid apabila $\mathrm{r}$ hitung > $\mathrm{r}$ table.Pembagian kuesioner pada seluruh sampel pada penelitian ini yaitu sejumlah 57 responden, sehingga menghasilkan nilai $\mathrm{r}$ tabel sebesar 0,261. Dari hasil yang ada, diperoleh $r$ hitung seluruh pernyataan > $r$ tabel $(0,261)$, artinya seluruh pernyataan dapat digunakan dalam penelitian ini. 
Hasil Uji Reliabilitas

Tabel 5 Hasil Uji Reliabilitas

\begin{tabular}{clcc}
\hline No & \multicolumn{1}{c}{ Variabel } & Cronbach's Alpha & Keterangan \\
\hline 1 & Konflik Interpersonal & 0,697 & Reliabel \\
2 & Beban Kerja & 0,721 & Reliabel \\
3 & Komunikasi & 0,727 & Reliabel \\
4 & Stres Kerja & 0,740 & Reliabel \\
\hline
\end{tabular}

Sumber: Hasil pengolahan data penelitian, 2018

Berdasarkan data pada Tabel 5 di atas, dapat dijelaskan bahwa semua variabel penelitian dinyatakan reliabel dimana Cronbach Alpha hitung > Cronbach Alpha yang disyaratkan $(0,6)$.

Hasil Uji Normalitas

Pada scatter plot Gambar 1 terlihat titik yang mengikuti garis diagonal menyebar kesemua arah daerah kurva normal. Hal ini dapat disimpulkan bahwa data mempunyai distribusi normal.

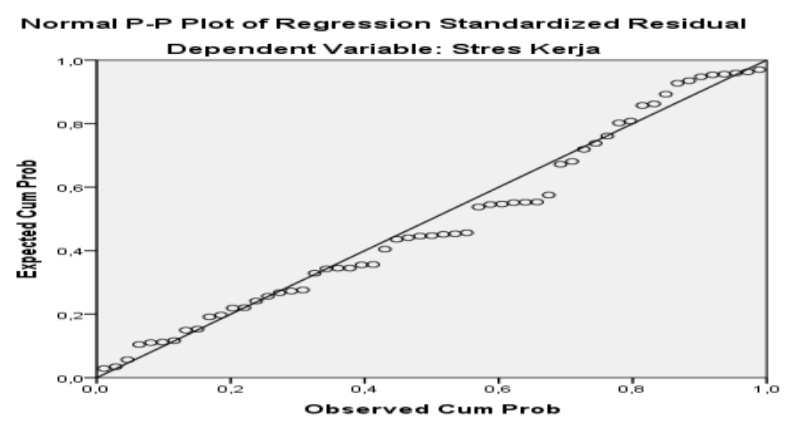

Gambar 1. Hasil Uji Normalitas (P-P Plot)

Sumber: Hasil pengolahan data, 2018

Hasil Uji Multikolinieritas

Berdasarkan hasil pengolahan data dengan program SPSS 20.0 diperoleh hasil bahwa dari kedua variabel bebas yang ada diketahui memiliki nilai VIF $<10$, yang artinya tidak ada gejala multikolinearitas dalam model regresi ini. 
Tabel 6. Hasil Uji Multikolinieritas

\begin{tabular}{|l|r|r|r|r|r|}
\hline \multirow{2}{*}{ Model } & \multicolumn{3}{|c|}{ Correlations } & \multicolumn{2}{c|}{ Collinearity Statistics } \\
\cline { 2 - 6 } & Zero-order & Partial & Part & \multicolumn{1}{c|}{ Tolerance } & \multicolumn{1}{c|}{ VIF } \\
\hline (Constant) & & & & & \\
X1 (Konflik Interpersonal) &, 061 &, 082 &, 072 &, 986 & 1,014 \\
X2 (Beban Kerja &,- 269 &,- 074 &,- 065 &, 807 & 1,239 \\
X3 (Komunikasi) &,- 473 &,- 417 &,- 401 &, 811 & 1,233 \\
\hline
\end{tabular}

a. Dependent Variable: Stres Kerja

Sumber: Hasil pengolahan data, 2018

\section{Hasil Uji Heteroskedastisitas}

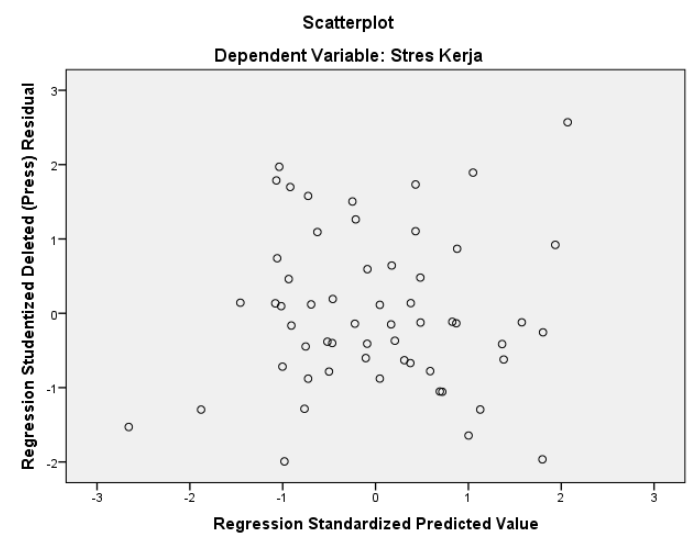

Gambar 2. Hasil Uji Heterokedastisitas Sumber: Hasil pengolahan data, 2018

Berdasarkan hasil pengolahan data dengan program SPSS 20.0 seperti pada gambar 4.3, diperoleh hasil bahwa titik-titik data tersebar di daerah antara $0-\mathrm{Y}$ dan tidak membentuk pola tertentu, maka model regresi yang terbentuk diidentifikasi tidak terjadi heteroskedastisitas.

Hasil Uji Regresi Linier Berganda

Tabel 7. Coefficients ${ }^{\mathrm{a}}$

\begin{tabular}{|c|c|c|c|c|c|}
\hline \multirow[t]{2}{*}{ Model } & \multicolumn{2}{|c|}{$\begin{array}{l}\text { Unstandardized } \\
\text { Coefficients }\end{array}$} & \multirow{2}{*}{$\begin{array}{c}\text { Standardized } \\
\text { Coefficients } \\
\text { Beta } \\
\end{array}$} & \multirow[t]{2}{*}{$T$} & \multirow[t]{2}{*}{ Sig. } \\
\hline & B & Std. Error & & & \\
\hline (Constant) & 4,469 & ,772 & & 5,792 &, 000 \\
\hline Konflik Interpersonal & 089 &, 149 & 072 & .598 &, 552 \\
\hline Beban Kerja &,- 083 &, 153 &,- 072 &,- 542 &, 590 \\
\hline Komunikasi &,- 526 & 158 &,- 445 & $-3,336$ &, 002 \\
\hline
\end{tabular}

Sumber: Hasil pengolahan data, 2018 

berikut:

Berdasarkan Tabel 7 maka dapat diketahui persamaan regresi linier berganda sebagai

a. Koefisien konflik interpersonal (X1) bernilai positif, hal ini berarti setiap peningkatan konflik interpersonal (X1) sebesar 1\% maka akan menyebabkan peningkatan stres kerja sebesar $(8,9 \%)$.

b. Koefisien beban kerja (X2) bernilai negatif, hal ini berarti setiap penurunan beban kerja (X2) sebesar $1 \%$ maka akan menyebabkan penurunan stres kerja $(8,3 \%)$.

c. Koefisien komunikasi (X3) bernilai negatif, hal ini berarti setiap penurunan komunikasi sebesar $1 \%$ maka akan menyebabkan peningkatan stres kerja sebesar $(52,6 \%)$.

Hal ini menunjukkan bahwa variabel yang paling dominan berpengaruh terhadap peningkatan stres kerja karyawan PT. Viking Engineering Batam adalah komunikasi, karena dengan adanya komunikasi yang baik maka akan mempengaruhi penurunan stres kerja karyawan.

\section{Hasil Uji Hipotesis}

Uji t (Parsial)

Hasil uji t menunjukkan bahwa konflik interpersonal dan beban kerja secara parsial berpengaruh tetapi tidak signifikan, hal ini dibuktikan dengan uji t yang menunjukkan hasil nilai signifikan lebih dari 0,05 yaitu sebesar 0,552 untuk variabel konflik interpersonal dan 0,590 untuk variabel beban kerja. Tetapi hasil uji t menunjukkan bahwa komunikasi secara parsial berpengaruh signifikan terhadap stress kerja, hal ini dibuktikan dengan uji t yang menunjukkan nilai signifikan lebih kecil dari 0,05 yaitu sebesar 0,002.

\section{Uji F (Simultan)}

Hasil pengujian menunjukkan bahwa variabel independent secara simultan (bersamasama) diperoleh nilai $\mathrm{F}$ hitung $=5,415$ dengan nilai probabiltas $\mathrm{F}$ (Sig) adalah sebesar 0,003 (Sig. 0,003<a0,05). Jadi dapat disimpulkan bahwa konflik interpersonal (X1), beban kerja (X2), dan komunikasi (X3) secara simultan memiliki pengaruh yang signifikan terhadap stres kerja (Y) karyawan PT. Viking Engineering Batam. 
Tabel 8. ANOVA ${ }^{\mathrm{a}}$

\begin{tabular}{|rl|r|r|r|r|r|}
\hline Model & & Sum of Squares & df & Mean Square & F & Sig. \\
\hline \multirow{4}{*}{1} & Regression & 4,176 & 3 & 1,392 & 5,415 &, $003^{\mathrm{b}}$ \\
& Residual & 13,623 & 53 &, 257 & & \\
& Total & 17,799 & 56 & & & \\
\hline
\end{tabular}

a. Dependent Variable: Stres Kerja

b. Predictors: (Constant), Komunikasi, Konflik Interpersonal, Beban Kerja

Sumber: Hasil pengolahan data, 2018

Penelitian ini menemukan pengaruh positif antara konflik interpersonal terhadap stress kerja, sehingga apabila semakin tinggi konflik interpersonal, maka stress kerja akan meningkat juga Dengan demikian konflik interpersonal berpengaruh positif tetapi tidak signifikan terhadap stress kerja. Hasil penelitian ini tidak sejalan dengan penelitian Hasby (2017) yang menyatakan bahwa konflik berpengaruh signifikan terhadap stres kerja.

Penelitian ini menemukan pengaruh negatif antara beban kerja terhadap stress kerja, sehingga apabila beban kerja menurun, maka stress kerja akan meningkat. Dengan demikian beban kerjaberpengaruh negatif tetapi tidak signifikan terhadap stress kerja. Hasil penelitian ini tidak sejalan dengan penelitian Hasby (2017) yang menyatakan bahwa beban kerja berpengaruh signifikan terhadap stres kerja.

Penelitian ini menemukan pengaruh negatif antara komunikasi terhadap stress kerja, sehingga apabila komunikasi menurun, maka stress kerja akan meningkat. Dengan demikian komunikasiberpengaruh negatif dan signifikan terhadap stress kerja. Hasil penelitian ini sejalan dengan penelitian Ashrahenny dan Ratnasari (2016), Wicaksono dan Ratnasari (2017), Hasby (2017) yang menyatakan bahwa komunikasi berpengaruh signifikan terhadap stres kerja.

\section{KESIMPULAN}

Berdasarkan hasil analisis yang telah dilakukan, maka dapat mengambil disimpulkan sebagai berikut:

1. Konflik interpersonal secara parsial berpengaruh tetapi tidak signifikan terhadap stres kerja karyawan PT. Viking Engineering Batam.

2. Beban kerja secara parsial berpengaruh tetapi tidak signifikan terhadap stres kerja karyawan PT. Viking Engineering Batam.

3. Komunikasi secara parsial mempunyai pangaruh yang signifikan terhadap stres kerja karyawan PT. Viking Engineering Batam. 
4. Konflik interpersonal, beban kerja, dan komunikasi secara bersama-sama (simultan) mempunyai pangaruh yang signifikan terhadap stres kerja karyawan PT. Viking Engineering Batam.

\section{DAFTAR PUSTAKA}

Ashrahenny \& Sri Langgeng Ratnasari. (2016). Pengaruh Gaya Kepemimpinan Dan Komunikasi Terhadap Kinerja Karyawan PT. Hi-Test (Laboratory Of Mechanical Testing). Jurnal Zona Manajemen. 8 (3).

Dewi, Tyas Hapsari \& Agustin Handayani. (2013). Kemampuan Mengelola Konflik Interpersonal di Tempat Kerja Ditinjau dari Persepsi terhadap Komunikasi Interpersonal dan Tipe Kepribadian Ekstrovet. Jurnal Psikologi Undip. 12 (1): 34-43.

Fitri, A. M. (2013). Analisa faktor-faktor yang berhubungan dengan kejadian stresskerja pada karyawan bank. Jurnal Kesehatan Masyarakat. 2 (1).

Ghozali, Imam. (2011). Aplikasi Analisis Multivariate Dengan Program IBM SPSS 19. Semarang: Badan Penerbit Universitas Diponegoro,

Handoko, Hani. (2009). Manajemen Sumber Daya Manusia. Cetakan keduapuluhdua. Yogyakarta: BPFE.

Haryanti, Faridah Aini, Puji Purwaningsih. (2013). Hubungan antara Beban Kerja dengan Stres Kerja Perawat di Instalasi Gawat Darurat RSUD Kabupaten Semarang. Jurnal Manajemen Keperawatan. 1 (1): 48-56.

Hasby. 2017. Pengaruh Konflik Kerja, Beban Kerja, dan Komunikasi Terhadap Stres Kerja Perawat Bagian Rawat Inap (Pada RSD. Petala Bumi Pekanbaru). JOM Fekon. 4 (1).

Ratnasari, Sri Langgeng. (2013). Manajemen Kinerja. Surabaya: Semesta Anugrah.

Samsudin, Sadili. (2009). Manajemen Sumber Daya Manusia. Bandung: Pustaka Setia.

Sari, Ria Puspita. (2015). Pengaruh Stres Kerja dan Konflik Kerja Terhadap Kinerja Karyawan Jambuluwuk Malioboro Boutique Hotel Yogyakarta. Yogyakarta: Universitas Negeri Yogyakarta.

Scannell, Marry. (2010). The Big Book of Conflict Resolution Games. United States of America: McGraw-Hill Companies, Inc.

Sugiyono. 2012. Metode Penelitian Kuantitatif Kualitatif dan R\&D. Bandung: Alfabeta.

Yuliawan, Eko. (2012). Pengaruh Stres Dan Konflik Terhadap Kinerja Pada PT. Pindad Bandung. Jurnal Wira Ekonomi Mikrosil. 2 (1): 11-21. 
Wicaksono, Bayu Dimas \& Sri Langgeng Ratnasari. (2017). Determinasi Komunikasi, Motivasi dan Lingkungan Kerja Terhadap Kinerja Karyawan di Perusahaan Umum (Perum) Bulog Sub Divre Kota Batam. Jurnal Bening. 4 (1). 